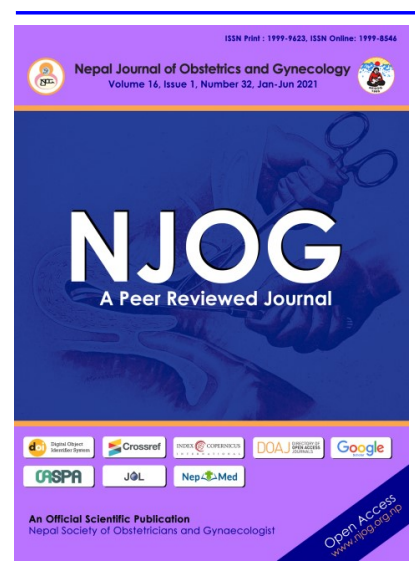

CORRESPONDENCE

Dr Birendra Bhagat

Department of Obstetrics and Gynecology

National Medical College, Birgunj, Nepal

E-mail:

bire_bhagat@yahoo.com

Phone: +977 9803502830

Received: June 1, 2021

Accepted: June 15, 2021

\section{Citation:}

Bhagat B. Surgical morbidity and its associated factors in ovarian carcinoma. Nep J Obstet Gynecol. 2021;16(32):124-128.

DOI: https://

doi.org/10.3126/

njog.v16i1.37919

\title{
Surgical Morbidity and its Associated Factors in Ovarian Carcinoma
}

Birendra Bhagat

Department of Obstetrics and Gynecology, National Academy of Medical Sciences, Kathmandu

\section{ABSTRACT}

Aims: To estimate 30-day surgical morbidity in patients with ovarian carcinoma and identify its associated factors.

Methods: This was an observational study conducted at two cancer hospitals, from October 2020 to March 2021. All women with ovarian carcinoma that underwent surgery were enrolled in the study. Incidence of surgical complications was recorded. Patients were followed up to the $30^{\text {th }}$ day post-operatively. Logistic regression analyses were used to evaluate the factors affecting surgical complications and their association was determined.

Results: A total of 31 patients were analyzed in this study. The incidence rate of surgical complications was $29 \%$. Total 11 complications occurred in nine patients (one intra-operatively and 10 post-operatively). Post-operative complications were wound infection $(n=4 ; 12.9 \%)$, urinary tract infection $(n=2$; $6.4 \%$ ); one each had post-op ileus, hemorrhage and deep vein thrombosis; and one mortality. Advancing age, increased Body Mass Index, primary surgery, higher surgical complexity score, increased operative time, increased blood loss, higher American Society of Anesthesiologists (ASA) score, presence of chronic disease were associated with surgical morbidity; and their hospital stay was longer $(\mathrm{p}=0.04)$.

Conclusion: The common complications were wound infection and urinary tract infection.

Keywords: complication, morbidity, ovarian cancer, surgery

\section{INTRODUCTION}

Ovarian cancer (OC) accounts for an estimated 313,959 new cases in 2020 which makes $3.4 \%$ of all cancer cases in women. The mortality rate due to ovarian carcinoma is $4.7 \%$ worldwide. ${ }^{1}$ Since it is difficult to diagnose ovarian carcinoma in the early stage, most of the patients presents in advanced, and incurable stage that leads to poor prognosis with decreased overall survival. ${ }^{2}$ At the early stages of carcinoma, staging surgery followed by platinum containing chemotherapy is the standard treatment modality. However, extended surgical procedures may be needed for advanced-stage disease.

Extensive surgical procedures are associated with substantial postoperative morbidity and mortality as well. The most common complications are urinary tract injury, intestinal injury, and hemorrhagic complications intra-operatively; and ileus, wound infection and pleural effusion post-operatively. ${ }^{3,4}$ Increasing age is strongly related to increased postoperative complications following abdominal surgery. ${ }^{5}$ Except age, comorbid conditions and stage of disease may be related to increased morbidity and mortality, but most reports are insufficiently powered to evaluate these associations. ${ }^{6}$ The extent and type of surgery, age of the patient, comorbid conditions, and performance status are very important predictors for shortterm post-operative outcomes. ${ }^{7}$ Mortality rates after primary cytoreductive surgery for advanced-stage ovarian carcinoma may reach up to $6.7 \%{ }^{8}$ Therefore, a careful intra-operative analysis of the risk factors and complications would represent the idea of follow-up during the recovery period.

The objective of this study is to estimate 30-day morbidity in patients with ovarian carcinoma and identify its associated factors. 


\section{METHODS}

This was a prospective observational study conducted at B.P Koirala Memorial Cancer Hospital and Bhaktapur Cancer Hospital for a period of three months in each hospital from October 2020 to March 2021. The American Society of Anesthesiologists (ASA) classification co-morbidities, CA-125, creatinine, albumin, Ultrasound/CT/MRI, surgical complexity score (SCS), type of surgery, extent of resection (complete resection $\mathrm{R}_{0}$ and incomplete resection $R_{1}$ ), ascitic fluid and blood loss were variables of study. Duration of surgery and occurrence of any intra-operative complications were recorded. The final stage of ovarian carcinoma according to FIGO was labeled post-operatively after obtaining histopathological report. The cut-off values under study were taken age (60 years), CA-125 (35 u/ml), ascites $(1000 \mathrm{ml})$, blood loss $(500 \mathrm{ml})$, albumin $(3.5 \mathrm{~g} / \mathrm{dl})$, BMI (Body Mass Index, $\left.25 \mathrm{~kg} / \mathrm{m}^{2}\right)$ and operative time (150minutes). Post-operative complications were defined as complications occurring within the first 30 days after surgery. Complications like surgical site infection, need of blood transfusion, pulmonary edema, renal failure, Deep Vein Thrombosis (DVT), UTI, sepsis, pneumonia, need for re-operation, re-hospitalization, duration of Intensive Care Unit (ICU) stay and hospital stay, and death were recorded. All patients were followed up till the $30^{\text {th }}$ day of surgery. Ethical approval was taken from NAMS.

Data analysis was carried out using SPSS 20. Frequency and descriptive analyses were performed. Logistic regression analyses were used to evaluate the factors affecting surgical complications and their association was determined. All $\mathrm{p}$ values $<0.05$ were considered statistically significant.

\section{RESULTS}

A total of 36 patients were enrolled in the study out of which 5 patients had a benign ovarian mass on the final histopathology report. The remaining 31 patients were further analysed. The median age of the patients was 52 years (range $=32-38$ ); most of them were post-menopausal $(\mathrm{n}=21 ; 68 \%)$ and multiparous ( $\mathrm{n}=29 ; 93.6 \%)$; and many of them had BMI of $\leq 25(\mathrm{n}=22 ; 71 \%)$. The most common symptom was awareness of mass per abdomen/abdominal distension (74\%). Most of the patients had good ASA performance status and none had ASA score greater than 2 . Pre-operatively morbid conditions were present in 11 patients and most of them had hypertension $(32.2 \%)$. [Table-1]

Interval surgery after neoadjuvant chemotherapy was done in $22(71 \%)$ patients. All patients underwent hysterectomy and salpingo-oophorectomy; and pelvic/para-aortic lymphadenectomy, intestinal resection, appendectomy and peritoneal resection were additional procedures. Most of the patients
Table-1: Preoperative parameters $(\mathrm{N}=31)$

\begin{tabular}{lcc}
\hline \multicolumn{2}{c}{ Variables } & $\mathrm{N}(\%)$ \\
\hline \multirow{2}{*}{ Serum albumin } & $\leq 3.5 \mathrm{~g} / \mathrm{dl}$ & $18(58 \%)$ \\
& $>3.5 \mathrm{~g} / \mathrm{dl}$ & $13(42 \%)$ \\
Serum CA 125 & $\leq 1000 \mathrm{u} / \mathrm{ml}$ & $23(74 \%)$ \\
& $>1000 \mathrm{u} / \mathrm{ml}$ & $8(26 \%)$ \\
ASA score & 1 & $10(32.3 \%)$ \\
& 2 & $21(67.7 \%)$ \\
Comorbidity (14 & Hypertension & $10(32.2 \%)$ \\
in 11 patients) & Diabetes mellitus & $3(9.7 \%)$ \\
& Hypothyroidism & $1(3.2 \%)$ \\
\hline
\end{tabular}

were able to achieve $\mathrm{R}_{0}$ resection ( $97 \%$ ) at surgery. The median duration of hospital stay and ICU stay after surgery were 10 days (range $=6-30$ ) and 1 day (range $=1-2$ ) respectively. Two cases could not get chemotherapy within 30 days of surgery. Two out of 31 patients required re-admission due to surgical site infection. Both of them underwent resuturing of the wound and both had delayed in initiating chemotherapy. [Table-2]

Table-2: Operative and post-operative details $(\mathrm{N}=31)$

There were total 11 complications in 9 patients.

\begin{tabular}{|c|c|c|}
\hline \multicolumn{2}{|c|}{ Variables } & $\mathrm{N}(\%)$ \\
\hline \multirow{2}{*}{$\begin{array}{l}\text { FIGO Stage of } \\
\text { ovarian cancer }\end{array}$} & Early (I and II) & $9(29 \%)$ \\
\hline & Late (III and IV) & $22(71 \%)$ \\
\hline \multirow{2}{*}{ Tumor grade } & High & $27(87 \%)$ \\
\hline & Low & $4(13 \%)$ \\
\hline \multirow{2}{*}{ Histology } & Serous & $29(93.6 \%)$ \\
\hline & Mucinous & $2(6.4 \%)$ \\
\hline \multirow{2}{*}{ Time of surgery } & Initial & $9(29 \%)$ \\
\hline & Interval & $22(71 \%)$ \\
\hline \multirow{5}{*}{$\begin{array}{l}\text { Extent of sur- } \\
\text { gery }\end{array}$} & Intestinal resection & $5(16.1 \%)$ \\
\hline & Omentectomy & $4(12.9 \%)$ \\
\hline & Peritoneal resection & $4(12.9 \%)$ \\
\hline & PLND/PALND & $3(9.7 \%)$ \\
\hline & Appendectomy & $2(6.4 \%)$ \\
\hline \multirow{2}{*}{ Operative time } & $\leq 150 \mathrm{~min}$ & $20(64.5 \%)$ \\
\hline & $>150 \mathrm{~min}$ & $11(35.5 \%)$ \\
\hline \multirow{4}{*}{$\begin{array}{l}\text { Estimated blood } \\
\text { loss } \\
\text { Amount of asci- } \\
\text { tes }\end{array}$} & $\leq 500 \mathrm{ml}$ & $30(96.8 \%)$ \\
\hline & $>500 \mathrm{ml}$ & $1(3.2 \%)$ \\
\hline & $\leq 500 \mathrm{ml}$ & $12(85.7 \%)$ \\
\hline & $>500 \mathrm{ml}$ & $2(14.3 \%)$ \\
\hline \multirow{2}{*}{ Resection } & $\mathrm{R} 0(\leq 1 \mathrm{~cm})$ & $30(96.8 \%)$ \\
\hline & $\mathrm{R} 1$ (>1 cm) & $1(3.2 \%)$ \\
\hline
\end{tabular}

The intra-operative complication was hemorrhage which occurred in one patient. Post-operative complications were: $4(12.9 \%)$ wound infections, 2 urinary infections and one each had DVT, per rectal bleed (residual disease of $>1 \mathrm{~cm}$ was left on sigmoid colon, ileostomy was done and had wound infection later) and ileus. Later she had a surgical site infection which prolonged her hospital stay for more than 30 days. The mortality occurred in one patient $(3.2 \%)$ after receiving the first cycle of adjuvant chemotherapy. 
The factors associated with surgical morbidity were evaluated using univariate analysis and only duration of hospital was statistically significant $(\mathrm{p}=0.04)$ despite its limitation by sample size. [Table-3]

Table-3: Univariate analysis

\begin{tabular}{|c|c|c|c|c|c|}
\hline & Factors & $\begin{array}{l}\text { Complica- } \\
\text { tions }(+)\end{array}$ & $\begin{array}{l}\text { Complica- } \\
\text { tions (-) }\end{array}$ & $\begin{array}{l}\text { Proportion } \\
(\%)\end{array}$ & p-value \\
\hline \multirow{2}{*}{ Age (yr) } & $\leq 60$ & 7 & 19 & 27 & \multirow{2}{*}{0.08} \\
\hline & $>60$ & 2 & 3 & 40 & \\
\hline \multirow{2}{*}{ BMI $\left(\mathrm{kg} / \mathrm{m}^{2}\right)$} & $\leq 25$ & 5 & 17 & 22.7 & \multirow{2}{*}{0.18} \\
\hline & $>25$ & 4 & 5 & 44.4 & \\
\hline \multirow{2}{*}{ Serum albumin (g/dl) } & $\leq 3.5$ & 5 & 13 & 27.8 & \multirow[t]{2}{*}{0.52} \\
\hline & $>3.5$ & 4 & 9 & 30.8 & \\
\hline \multirow{2}{*}{ Stage } & Early & 3 & 6 & 33.3 & \multirow{2}{*}{0.06} \\
\hline & Advanced & 6 & 16 & 27.3 & \\
\hline \multirow{2}{*}{ Surgical approach } & Primary & 3 & 6 & 33.3 & \multirow{2}{*}{0.06} \\
\hline & Interval & 6 & 16 & 27.3 & \\
\hline \multirow{2}{*}{$\begin{array}{l}\text { Surgical Complexity } \\
\text { Score (SCR) }\end{array}$} & Mild & 6 & 15 & 28.6 & \multirow{2}{*}{0.40} \\
\hline & Intermediate & 3 & 7 & 30 & \\
\hline \multirow{2}{*}{ CA125 level (IU) } & 1000 & 7 & 16 & 30.4 & \multirow{2}{*}{0.96} \\
\hline & 1000 & 2 & 6 & 25 & \\
\hline \multirow{2}{*}{ Operative time (mins) } & $\leq 150$ & 5 & 15 & 25 & \multirow[t]{2}{*}{0.23} \\
\hline & $>150$ & 4 & 7 & 36.4 & \\
\hline \multirow{2}{*}{$\begin{array}{l}\text { Estimated blood loss } \\
(\mathrm{ml})\end{array}$} & $\leq 500$ & 8 & 22 & 26.7 & \multirow{2}{*}{0.11} \\
\hline & $>500$ & 1 & 0 & 100 & \\
\hline \multirow{2}{*}{ Amount of ascites (ml) } & $\leq 500$ & 4 & 8 & 33.3 & \multirow{2}{*}{0.18} \\
\hline & $>500$ & 0 & 2 & 0 & \\
\hline \multirow{2}{*}{ ASA score } & 1 & 2 & 8 & 20 & \multirow{2}{*}{0.89} \\
\hline & 2 & 7 & 14 & 33.3 & \\
\hline \multirow{2}{*}{ Chronic disease } & Present & 5 & 7 & 41.7 & \multirow{2}{*}{0.33} \\
\hline & Absent & 4 & 15 & 21.1 & \\
\hline \multirow{2}{*}{$\begin{array}{l}\text { Duration of hospital stay } \\
\text { (days) }\end{array}$} & $\leq 10$ & 4 & 19 & 17.4 & \multirow{2}{*}{0.04} \\
\hline & $>10$ & 5 & 3 & 62.5 & \\
\hline
\end{tabular}

\section{DISCUSSION}

The complication rate in this study was $29 \%$. Intra-operatively, one patient had massive blood loss of $1200 \mathrm{ml}$ due to the increased vascularity and dense perilesional adhesion of the ovarian mass. Post-operatively, the most common complication in this study was surgical site infection followed by UTI. Surgical site infection was found to be the most common complication in a study by Gunaken. ${ }^{3}$ Whereas most of the other studies had UTI being the most common complication. ${ }^{9,10}$ The reason for the low incidence of UTI in this study may be the prolonged use of antibiotics from the day of surgery to the day of discharge. One patient with high surgical complexity score and CA-125 level developed DVT after three weeks of surgery. Surgical complexity score and CA-125 level have been established risk factors of DVT. ${ }^{11}$ Only one patient died within 30 days of follow-up. The cause of the death couldn't be identified as she died at home after receiving the first cycle of chemotherapy. 30 day-mortality rate was $3.2 \%$ in our study which is lower than the mortality rate $(5.6 \%)$ reported by Melissa et al, but the latter considered only advanced ovarian cases. ${ }^{12}$
On univariate analysis age, BMI, surgical approach, surgical complexity score, ASA score, amount of blood loss, operative time and presence of the chronic disease didn't show significant association with the early morbidity that occurred due to surgery. But, the rate of complication was higher with these factors when compared to their counterparts. The median age of diagnosis of ovarian carcinoma in our study was 52 years, the youngest being 32 and the oldest 82 years. The incidence rate of complication was higher in the age group above 60 years. This is similar to a study conducted by Gunakan et al where the mean age of diagnosis was 53 years and advanced age was significantly associated with post-operative morbidity. ${ }^{3}$ Their study reported a morbidity rate of $37.5 \%$ in patients older than 75 years of age. Chereau et al reported no difference in complication rate in patients above and below 70 years but elderly patients had a smaller number of peritoneal surgery and paraaortic lymphadenectomy. ${ }^{10}$ Obese patients are considered to be at increased risk of surgical complications because they have associated other comorbidities that may significantly increase the risk of surgical morbidity. ${ }^{13}$ In a study by Smits et al, wound infection was significantly associat- 
with obesity. ${ }^{9}$ Other surgical complications were similar in obese and non-obese counterparts except obese patients had prolonged hospital stay. In this study, $75 \%$ of wound infections occurred in obese patients. Wound infection has been associated with prolonging hospital stay. ${ }^{14}$ Two patients with wound infection in this study required re-admission for resuturing and both the patients had delays in initiating chemotherapy.

The surgical approach and surgical complexity score have been linked to increased complications following surgery. In a recent study comparing primary surgery vs interval debulking surgery, Fagotti et al reported an increased incidence of complications in the primary surgery group than the IDS group $(46.4 \%$ vs $9.5 \%)$, which was statistically significant. ${ }^{15}$ In this study, the surgical complications rate was higher in primary surgery $(33.3 \%)$ than in IDS $(27.3 \%)$ though it was not statistically significant. Most of the patients in this study underwent IDS due to the COVID-19 pandemic during the study period. Aletti et al described a surgical complexity scoring system in a study. ${ }^{16}$ They included 219 patients in which major surgical morbidity rate was $16.7 \%$ and the surgical complexity score (SCS) was significantly associated with 30-day morbidity. In another study, the complication rate depended upon the number of extended procedures performed. ${ }^{17}$ The patient who had no extended procedure had a complication rate of $7.3 \%$ which increased to $12.9 \%$ for 1 procedure, $28.4 \%$ for 2 procedures and $30 \%$ for greater than 3 procedures. Knowing that patients who require extended procedures are at higher risk, identifying them with imaging modalities to predict resectability has reported mixed opinions. ${ }^{18,19}$ Recently there is increasing interest in determining resectability through laparoscopy prior to laparotomy. ${ }^{20}$ In this study none of the patients had severe surgical complexity score. The complications rate in mild SCS was $28.6 \%$ and intermediate SCS was $30 \%$. Since most of the patients underwent IDS, a less surgical complexity score was obvious. Most of the patients presented in latestage disease (stage III and IV). An extensive surgical procedure involving bowel resection, anastomosis, stoma formation was required to remove all the gross disease in the advanced stage, but complications were not statistically associated when compared with early-stage disease (I and II). The reason may be bowel resection is considered as a standard part of the surgery; it's not considered as a part of complications.

The presence of chronic disease, higher ASA value, lower albumin level, higher operative time and higher amount of blood loss has been associated with increased incidence of surgical morbidity in other studies. ${ }^{3,10}$ In this study, though they had higher incidence rate of surgical complications, a signif- icant association was not reached. This may be due to the relatively small sample size in the study group.

There were few limitations in this study. The number of patients visiting these hospitals was less due to the COVID-19 pandemic so the sample size was small when patients were recruited prospectively. Most of the patients underwent interval cytoreduction surgery which might have decreased early post-operative surgical morbidity. The factors considered in this study couldn't reach the statistical significance which may be because of its small sample size. We recommend further study with a higher number of samples to establish co-relation.

\section{CONCLUSIONS}

The complication rate was $29 \%$ and the most common complications were wound infection and urinary tract infection. The duration of hospital-stay significantly increased in patients with postoperative complications.

\section{ACKNOWLEDGEMENT}

I would like to thank Meena Jha, Rijuta Joshi, Binuma Shrestha, Sristee Shrestha Prajapati and Eliza Shrestha for their help in reviewing the manuscript.

\section{REFERENCES}

1. Sung H, Ferlay J, Siegel RL, Laversanne M, Soerjomataram I, Jemal A, Bray F. Global Cancer Statistics 2020: GLOBOCAN Estimates of Incidence and Mortality Worldwide for 36 Cancers in 185 Countries. Cancer J Clin. 2021;71 (3):209-249. https://doi.org/10.3322/caac.21660

2. Shah S, Hishikar VA. Incidence and management of ovarian tumors. Bombay Hospital J. 2008;50:30-3. Available from http:// www.bhj.org.in/journal/2008_5001_jan/ download/bombay-hospital-journal.pdf

3. Günakan E, Tohma YA, Tunç M, Akıllı H, Şahin H, Ayhan A. Factors associated with surgical morbidity of primary debulking in epithelial ovarian cancer. Obstet Gynecol Sci. 2020;63 (1):64-71. https://doi.org/10.5468/ ogs.2020.63.1.64

4. Aletti GD, Santillan A, Eisenhauer EL, Hu J, Aletti G, Podratz KC, et al. A new frontier for quality of care in gynecologic oncology surgery: multi-institutional assessment of shortterm outcomes for ovarian cancer using a riskadjusted model. Gynecol Oncol. 2007;107:99106. j.ygyno.2007.05.032

5. Massarweh NN, Legner VJ, Symons RG, McCormick WC, Flum DR. Impact of advancing age on abdominal surgical outcomes. Arch 
Surg. $\quad 2009 ; 144(12): 1108-14$. https:// jamanetwork.com/journals/jamasurgery/ fullarticle/405554

6. Vergote I, Trope CG, Amant F, Kristensen GB, Ehlen T, Johnson N, et al. Neoadjuvant chemotherapy or primary surgery in stage IIIC or IV ovarian cancer. N Engl J Med. 2010;363(10):943 -53. https://doi.org/10.1056/nejmoa0908806

7. Alphs HH, Zahurak ML, Bristow RE, DiazMontes TP. Predictors of surgical outcome and survival among elderly women diagnosed with ovarian and primary peritoneal cancer. Gynecol Oncol. 2006;103:1048-53. http:// dx.doi.org/10.1016/j.ygyno.2006.06.019

8. Gerestein CG, Damhuis RA, Burger CW, Kooi GS. Postoperative mortality after primary cytoreductive surgery for advanced stage epithelial ovarian cancer: a systematic review. Gynecol Oncol. 2009;114(3):523-7. http:// dx.doi.org/10.1016/j.ygyno.2009.03.011

9. Smits A, Lopes A, Das N, Kumar A, Cliby W, Smits E, et al. Surgical morbidity and clinical outcomes in ovarian cancer - the role of obesity. BJOG. 2016;123:300-8. http:// dx.doi.org/10.1111/1471-0528.13585

10. Chereau E, Ballester M, Selle F, Rouzier R, Darai E. Ovarian cancer in the elderly: Impact of Surgery on Morbidity and Survival. Eur J Surg Oncol. 2011;37:537-42. https://doi.org/10.1016/ j.ejso. 2011.03 .136

11. Abu Saadeh F, Norris L, O'Toole S, Gleeson N. Venous thromboembolism in ovarian cancer: incidence, risk factors and impact on survival. Eur J Obstet Gynecol Reprod Biol. 2013;170 (1):214-8. j.ejogrb.2013.06.004

12. Thrall MM, Goff BA, Symons RG. Thirty-day mortality after primary cytoreductive surgery for advanced ovarian cancer in the elderly. Obstet Gynecol. 2011;118:537-47. http:// dx.doi.org/10.1097/AOG.0b013e31822a6d56

13. Bamgbade OA, Rutter TW, Nafiu OO, Dorje P. Postoperative complications in obese and nonobese patients. World J Surg. 2007;31:55660 discussion 61. https://doi.org/10.1007/s00268 $-006-0305-0$
14. Pierpont YN, Dinh TP, Salas RE, Johnson EL, Wright TG, Robson MC, et al. Obesity and surgical wound healing: a current review. Obesity. 2014;2014:638936. doi.org/10.1155/2014/638936

15. Fagotti A, Ferrandina MG, Vizzielli G, Pasciuto T, Fanfani F, Gallotta V, et al. Randomized trial of primary debulking surgery versus neoadjuvant chemotherapy for advanced epithelial ovarian cancer (SCORPIONNCT01461850). Int J Gynecol Cancer. 2020;30 (11):1657-64. https://doi.org/10.1136/ijgc-2020 $-001640$

16. Aletti GD, Dowdy SC, Podratz KC, Cliby WA. Relationship among surgical complexity, shortterm morbidity, and overall survival in primary surgery for advanced ovarian cancer. Am J Obstet Gynecol. 2007;197:676.e1-7. https:// doi.org/10.1016/j.ajog.2007.10.495

17. Patankar S, Burke WM, Hou JY. Risk stratification and outcomes of women undergoing surgery for ovarian cancer. Gynecol Oncol. 2015;138(1):62-9. https://dx.doi.org/10.1016\% 2Fj.ygyno.2015.04.037

18. Nick AM, Coleman RL, Ramirez PT, Sood AK. A framework for a personalized surgical approach to ovarian cancer. Nat Rev Clin Oncol. 2015;12:239-45. https:// dx.doi.org/10.1038\%2Fnrclinonc.2015.26

19. Glaser G, Torres M, Kim B. The use of CT findings to predict extent of tumor at primary surgery for ovarian cancer. Gynecol Oncol. 2013;130:280-3. https://doi.org/10.1016/ j.ygyno.2013.05.007

20. Fagotti A, Vizzielli G, De Iaco P. A multicentric trial (Olympia-MITO 13) on the accuracy of laparoscopy to assess peritoneal spread in ovarian cancer. Am J Obstet Gynecol. 2013;209:462 e1-462 e11. https:// doi.org/10.1016/j.ajog.2013.07.016 